Article

\title{
The Fabrication of Au@C Core/Shell Nanoparticles by Laser Ablation in Solutions and Their Enhancements to a Gas Sensor
}

\author{
Xiaoxia $\mathrm{Xu}^{\dagger}{ }^{\dagger}$, Lei Gao ${ }^{\dagger}$ and Guotao Duan * (D) \\ Key Laboratory of Materials Physics, Anhui Key Laboratory of Nanomaterials and Nanotechnology, \\ Institute of Solid State Physics, Chinese Academy of Sciences, Hefei 230031, China; xxxu@issp.ac.cn (X.X.); \\ lgao@issp.ac.cn (L.G.) \\ * Correspondence: duangt@issp.ac.cn \\ t These authors contributed equally to this work.
}

Received: 16 March 2018; Accepted: 29 May 2018; Published: 1 June 2018

\begin{abstract}
A convenient and flexible route is presented to fabricate gold noble metal nanoparticles wrapped with a controllable ultrathin carbon layer $(\mathrm{Au} @ \mathrm{C})$ in one step based on laser ablation of the noble metal targets in toluene-ethanol mixed solutions. The obtained metal nanoparticles were $<20 \mathrm{~nm}$ in size after ablation, and the thickness of the wrapped ultrathin carbon layer was $2 \mathrm{~nm}$ in a typical reaction. The size of the inner noble metal nanoparticles could be controlled by adjusting the power of laser ablation, and the thickness of the ultrathin carbon layer can be controlled from 0.6 to $2 \mathrm{~nm}$ by laser ablation in different components of organic solution. Then the resultant $\mathrm{Au} @ \mathrm{C}$ core/shell nanoparticles were modified on the surface of $\operatorname{In}_{2} \mathrm{O}_{3}$ films through a sol-gel technique, and the hydrogen sulfide $\left(\mathrm{H}_{2} \mathrm{~S}\right)$ gas-sensing characteristics of the products were examined. Compared to pure and Au-modified $\operatorname{In}_{2} \mathrm{O}_{3}$, the Au@C-modified $\mathrm{In}_{2} \mathrm{O}_{3}$ materials exhibited a revertible and reproducible performance with good sensitivity and very low response times (few seconds) for $\mathrm{H}_{2} \mathrm{~S}$ gas with a concentrations of 1 to $5 \mathrm{ppm}$ at room temperature. Evidence proved that the ultrathin carbon layer played an important role in the improved $\mathrm{H}_{2} \mathrm{~S}$ sensor performance. Other noble metals wrapped by the homogeneous carbon shell, such as Ag@C, could also be prepared with this method.
\end{abstract}

Keywords: laser ablation; core/shell nanostructure; ultrathin carbon layer; gas sensing

\section{Introduction}

Core/shell nanostructure nanocomposites, in which the inner nanoparticle is encapsulated and protected against agglomeration, adsorption, or chemical reaction by an outer shell, have attracted much attention due to their fantastic physical, chemical, biological, and catalytic properties [1-3]. The thickness of the outer shell plays a significant role in the performance of the nanocomposites. For example, the surface enhanced Raman scattering (SERS) of noble metal nanomaterials coated with special materials shell to detect some target molecules need the outer shell in nanometer scale, and the SERS signal will be weakened, or disappear, if the coating shell is too thick [4]. On the other hand, graphene or graphene-like structure materials process unique chemical and physical properties and have become a hot research topic since they appeared. As a sheath coating on nanoparticles they could effectively enhance the properties of the nanoparticles [5], and it requires the thickness of the outer carbon shell with one or several layers. Now there are even many methods to coat the nanoparticles, such as vapor deposition [6-8], solution dipping [9,10], sol-gel coating, and so on [11]. However, it is still a challenge to obtain the nanoparticles wrapped with ultrathin and homogeneous outer layers with the above methods, especially for the noble metal nanoparticles. 
Laser ablation of the metal targets in liquids could easily and effectively prepare such structure materials in only one step [12-14]. Compared with the conventional method, it is an attractive green and versatile technique to prepare various metal nanoparticles, such as $\mathrm{Au}, \mathrm{Ag}$, $\mathrm{Pt}$, and $\mathrm{Ni}$, etc. The metal nanoparticles obtained by this method have excellent chemistry, metastable composition, easily functionalizable surfaces, high purity, and good dispersity, etc., and these properties are closely related to the applications such as catalysis and SERS research [13,15]. For example, using $532 \mathrm{~nm}$ output from a pulsed Nd:YAG laser (10 ns, $10 \mathrm{~Hz}$ ) Shaji et al. successfully obtained $\mathrm{ZnO}$ nanoparticles with zinc metal as the target in distilled water at different water temperatures, and found that the morphology, structure, chemical state and optical properties of $\mathrm{ZnO}$ nanoparticles were closely related with the temperature and laser fluence [16]. Kautek et al. prepared $\mathrm{Ni} / \mathrm{NiO}_{\mathrm{x}}$ core/shell nanoparticles in water and alcoholic fluids, and the nature of the fluid, the laser fluence, and the number of laser pulses decided the size distribution of the products. Through the changes of these parameters, the size distribution of $\mathrm{Ni} / \mathrm{NiO}_{\mathrm{x}}$ core/shell nanoparticles was changed from 10 to $30 \mathrm{~nm}$ [17]. If only organic solvents are chosen as the liquids, it will be an ideal carbon source to form ultrathin carbon layers. By two sequential processes during ablation, i.e., formation of the noble metal nanoparticles and subsequent carbon-deposition, the homogeneous and ultrathin carbon layer-wrapped noble metal nanoparticles will be obtained in one step with this method. The production with a unique structure will be an effective and excellent modifying material for application of a semiconductor metal oxide-based gas sensor.

Semiconductor metal oxide-based gas sensors have received extensive research because they can detect the toxic, harmful, inflammable, or explosive gases quickly, efficiently, and accurately [18-21]. Among varieties of sensitive materials, indium oxide $\left(\operatorname{In}_{2} \mathrm{O}_{3}\right)$ is a promising material for semiconductor gas sensor due to its peculiar properties, such as a wide band gap $(3.56 \mathrm{eV})$, low resistance, and good catalysis [22-24]. Up to now, $\operatorname{In}_{2} \mathrm{O}_{3}$ has been widely applied to detect $\mathrm{H}_{2}, \mathrm{CO}, \mathrm{O}_{3}$, and volatile organic compounds, etc. It is well known that the gas-sensing mechanism of semiconductors is based on the oxidation-reduction reaction between the surface of the sensor material and the test gas [25,26]. In order to improve the gas response and selectivity of semiconductor oxides, a nanoparticle-modifying method is often adopted, especially noble metal nanoparticles [27]. The reason is that it can easily change the electronic structure or space charge layer thickness of sensing films and improve the gas sensing performance. Herein, we report that modifying $\mathrm{Au}$ and $\mathrm{Au} @ \mathrm{C}$ nanoparticles prepared by laser ablation in liquid onto $\mathrm{In}_{2} \mathrm{O}_{3}$ film can lead to a greatly enhanced sensing sensitivity to $\mathrm{H}_{2} \mathrm{~S}$ at room temperature.

\section{Experimental Section}

\subsection{Au and Au@C Colloidal Solution Preparation}

Typically, a gold (or silver) plate $\left(99.99 \%, 1.5 \times 1 \mathrm{~cm}^{2}\right.$, purchased from Sinopharm Chemical Reagent Limited Corporation, Shanghai, China) is fixed on a bracket in a quartz glass vessel and immersed in $10 \mathrm{~mL}$ toluene-ethanol mixed solution with a volume ratio of 9:1. The vessel was placed on a horizontal platform. The plate in the solution was irradiated, while the solution was continuously stirred, by the first harmonic of a Nd:YAG (yttrium aluminum garnet) laser (1064 nm in wavelength, $10 \mathrm{~Hz}$ in frequency, and $10 \mathrm{~ns}$ in pulse duration) with the power of $60 \mathrm{~mJ} /$ pulse and the spot size of about $2 \mathrm{~mm}$ in diameter on the plate. A purple colloidal solution was formed during the irradiation for $20 \mathrm{~min}$. The ablation of the target in water was also carried out for reference. After ablation, the solution was centrifuged at 12,000 rpm, and the obtained Au@C colloidal solution was rinsed several times with ethanol in order to remove the residual toluene and dehydrated at $60^{\circ} \mathrm{C}$ for $12 \mathrm{~h}$. The Au colloidal solution prepared in water was centrifuged under the same condition and Au nanoparticles were dispersed in $2 \mathrm{~mL}$ ethanol.

\subsection{Preparation of $\mathrm{Au}$ or $\mathrm{Au} @ \mathrm{C}$ Modified $\mathrm{In}_{2} \mathrm{O}_{3}$ Film-Based Sensing Devices}

Firstly, $1.0 \mathrm{~g}$ indium nitrate hydrate powder was dispersed in $80 \mathrm{~mL}$ deionized water with continual stirring by a magnetic rotor for $10 \mathrm{~min}$. Subsequently, $0.6 \mathrm{~g}$ urea was added to the above colorless precursor solution and stirred for $20 \mathrm{~min}$ to obtain a mixture solution. Secondly, a 2D ordered polystyrene spheres (PS) colloidal monolayer template on a glass slide with the sphere diameter of 
$1000 \mathrm{~nm}$ was prepared by air/water interfacial assembly. Then the PS monolayer colloidal template on the glass slide was peeled off and floated onto the surface of pure water in a beaker due to surface tension of the solution. A ceramic tube was used to pick up the PS monolayer colloidal template from the bottom of liquid surface and dried at $80{ }^{\circ} \mathrm{C}$ for $2 \mathrm{~h}$. Thirdly, the ceramic tube coated by the PS monolayer colloidal template was impregnated to the above mixture solution and transferred into a sealed stainless steel reactor and kept at $90{ }^{\circ} \mathrm{C}$ for $2 \mathrm{~h}$. After the reaction the ceramic tube was washed by deionized water three times to remove the excess mixture solution. Fourthly, the ceramic tube was heated at $300{ }^{\circ} \mathrm{C}$ for $2 \mathrm{~h}$ to burn the PS template away and the $\mathrm{In}_{2} \mathrm{O}_{3}$ thin film was formed on the tube. Finally, Au and Au@C nanoparticles were modified onto the $\operatorname{In}_{2} \mathrm{O}_{3}$ thin film by impregnating it in the Au and Au@C colloidal ethanol solution and dried at $60{ }^{\circ} \mathrm{C}$ for $1 \mathrm{~h}$. Thus, the Au- or Au@C-modified $\mathrm{In}_{2} \mathrm{O}_{3}$ film-based sensing devices were fabricated.

\subsection{The Gas Sensing Measurements and Characterization Methods}

All the gas sensing performances were measured in a static system with a volume of $20 \mathrm{~L}$ by the measurement of electric circuit at room temperature, in which a fixed resistor with the values ranging from 0.1 to $100 \mathrm{M}$ ohm were connected in series on a circuit board to adjust the voltage of the sensor. This system was consisted by several sections such as manometers, electromagnetic cut-off valves, hydrometer, measuring chamber, gas pressure stabilizers and the signal processing system. Agilent U8002A DC power (San Jose, CA, USA) provided a $10 \mathrm{~V}$ regulated power supply, and Agilent mod. U3606A (San Jose, CA, USA) collected and recorded the voltage change on the fixed resistor by the computer. The $\mathrm{H}_{2} \mathrm{~S}$ gas with required quantities was injected into the measure system by a syringe, which was calculated by the ideal gas equation of state from the pristine gas cylinders of 10,000 ppm obtained commercially. Firstly the pure air was introduced into the measure system for 30 min and guaranteed the sensor's ambience with $60 \% \mathrm{RH}$, then a concentration of diluted $\mathrm{H}_{2} \mathrm{~S}$ gas was injected and kept for $30 \mathrm{~s}$, and the corresponding electric response signal of gas sensor was recorded by computer. Then the pure air was introduced into the measure system again to remove the $\mathrm{H}_{2} \mathrm{~S}$ gas and after $60 \mathrm{~s}$ another concentration of diluted $\mathrm{H}_{2} \mathrm{~S}$ gas was injected and kept for $30 \mathrm{~s}$ again, then cycled the above operation. In order to evaluate the selectivity performances of the sensor, some oxidizing or reducing gases such as $\mathrm{C}_{3} \mathrm{H}_{6} \mathrm{O}, \mathrm{H}_{2}, \mathrm{C}_{2} \mathrm{H}_{6} \mathrm{O}, \mathrm{NH}_{3}, \mathrm{CH}_{4}$, and $\mathrm{SO}_{2}$ were injected into the measurement system. A vaporizer was used to control the environmental humidity in the system, and a lab-made software was used to control the heating voltage and record data.

The resultant products were characterized by a field emission scanning electron microscope (FE-SEM, Hitachi, SU8020, Tokyo, Japan) and a transmission electron microscope (TEM, JEM-200CX, Tokyo, Japan). The optical absorption spectra were measured on a Cary-5E UV-VIS-NIR spectrophotometer (San Jose, CA, USA). The Raman spectra were recorded on a microscopic confocal Raman spectrometer (Renishaw inVia Reflex, London, UK) using a laser beam of $532 \mathrm{~nm}$ wavelength, $1 \mathrm{~mW}$ power and $5 \mu \mathrm{m}$ spot size on the sample area. The gravimetric analysis was measured on TGA Q5000IR (Cranston, RI, USA).

\section{Results and Discussion}

In a typical reaction, using a toluene-ethanol mixed solution with a volume ratio of 9:1 as the laser ablation liquid, Au nanoparticles wrapped with an ultrathin carbon layer (Au@C) are obtained. The morphology and structure of the products are measured by TEM, as shown in Figure 1. It can be seen that the inner Au nanoparticles are spherical in structure with a diameter in the range of 5 to $15 \mathrm{~nm}$ and a mean size of $12 \mathrm{~nm}$. Figure $1 \mathrm{~b}$ is a larger image of Figure 1a, and the particles are much larger than the ones shown in Figure 1a. From the high-resolution TEM image of a partial particle, the clear crystal lattice can be discovered with a spacing of the lattice fringe of $0.24 \mathrm{~nm}$, corresponding to the (111) plane of $\mathrm{Au}$. Such a higher crystal surface index can ensure the prepared material with a better catalytic activity. The outer ultrathin carbon layer is about $2 \mathrm{~nm}$ in thickness with a spacing of the lattice fringe of $0.34 \mathrm{~nm}$, which corresponds to the (001) plane of carbon. In addition, the energy spectrum of Au@C nanoparticles is also shown in the Figure S1, and it can be seen that the Au nanoparticles are indeed coated by a carbon layer, 
which corresponds to the results of high-resolution transmission electron microscopy (HRTEM). At the same conditions, using water solution as laser ablation liquids only Au nanoparticles with a size below $20 \mathrm{~nm}$ are formed after laser ablation of the Au target, and no carbon shell appears, as shown in Figure S2. Using water solution as laser ablation liquids only Ag nanoparticles without carbon shell is prepared with a size of about $50 \mathrm{~nm}$ after laser ablation of Ag target shown in Figure S3. Similarly, ablation of Ag target in the toluene-ethanol mixed solution with the same volume ratio leads to the wrapped Ag nanoparticles (Ag@C) with the average size of 15 nm, as shown in Figure S4. In addition, the energy spectrum of Ag@C nanoparticles is also shown in the Figure S5, which indicates that the Ag@C samples have been prepared successfully by the same method. The coating layer is also about $2 \mathrm{~nm}$ in thickness. In order to assess the amount of carbon in the shells of Au@C nanoparticles, a gravimetric analysis is measured and the results can be seen in the Figure S6. It can be seen that there is a mass loss of $0.94 \%$ at first, which corresponds to the small adsorbed molecules in the samples such as the water molecules. Then the other mass loss occurs from $199.7^{\circ} \mathrm{C}$, which corresponds to the combustion of the carbon shells. This indicates that the amount of carbon in the shells of Au@C nanoparticles is about 3.96\%. The selected area electronic diffraction of Ag@C illustrated that the inner Ag nanoparticles have a good crystallinity. With this method, other types of metal nanoparticles wrapped with ultrathin carbon layers may also be obtained.
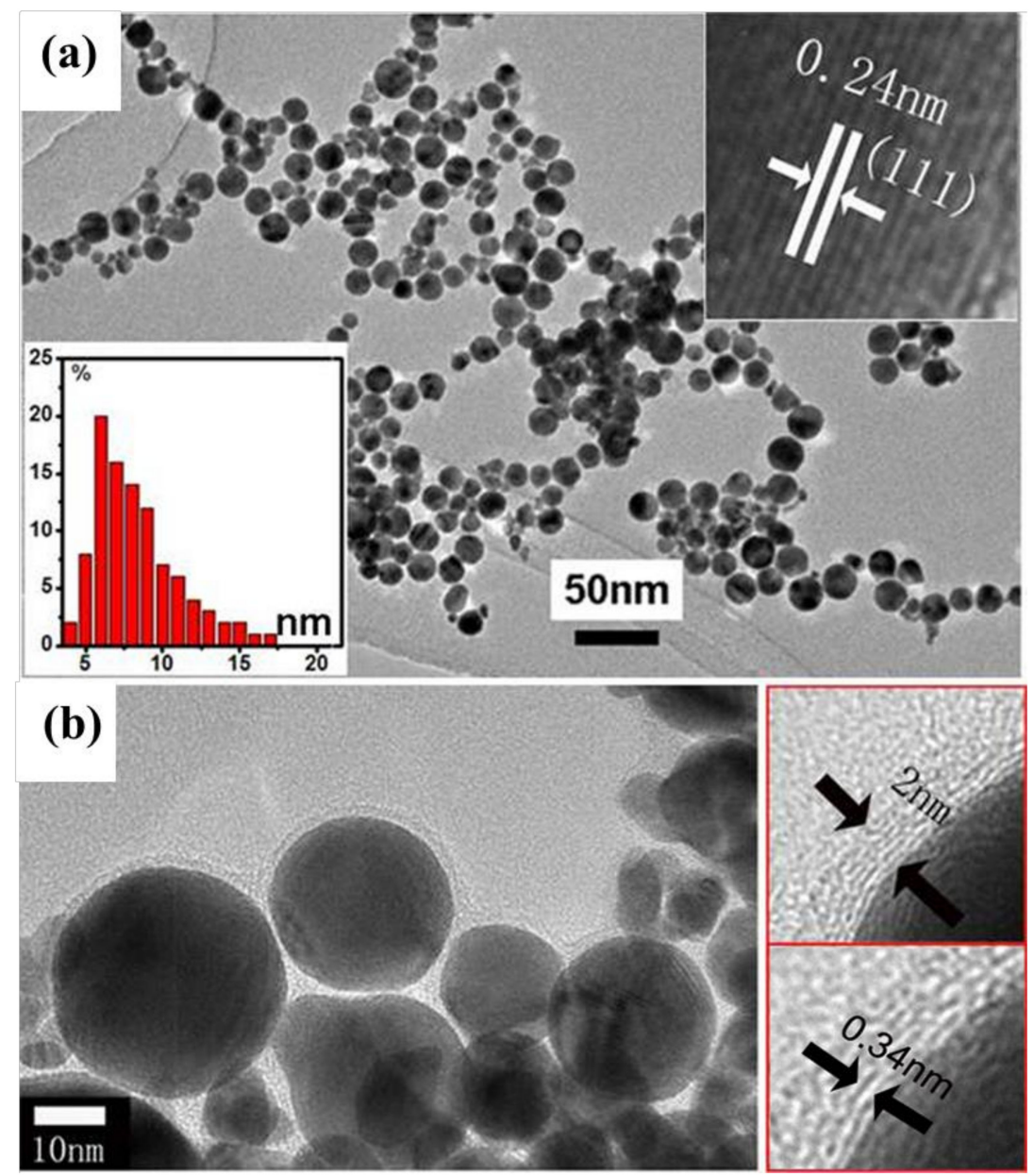

Figure 1. The TEM examination of the products induced by laser ablation of Au target in toluene-ethanol solution with the volume ratio 9:1 and the power of $60 \mathrm{~mJ} /$ pulse. (a): TEM image at low magnification. Insets: particle size distribution (lower-left) and high resolution TEM image of a partial particle showing Au (111) plane fringe (upper-right); and (b) local magnified image of (a). The insets show the thickness of the ultrathin carbon layer (upper-right) and the fringe spacing in the shell layer (lower-right). 
The optical absorbance spectra of Au and Au@C colloidal solutions are shown in Figure 2a. In the measurement of optical absorbance spectra of all the samples, which are prepared at the same conditions with the power of $60 \mathrm{~mJ} /$ pulse and the spot size of about $2 \mathrm{~mm}$ in diameter on the plate for $20 \mathrm{~min}, 3 \mathrm{~mL}$ sample water solution $(0.1 \mathrm{~g} / \mathrm{L})$ is put into a quartz cell with $12.5 \times 12.5 \times 45 \mathrm{~mm}^{3}$ and the same quartz cell with $3 \mathrm{~mL}$ pure water solution is used as a reference. Then they are measured with a wavelength of 300 to $800 \mathrm{~nm}$. For ablation of the Au target in water, there exists an absorption band around $520 \mathrm{~nm}$, which corresponds to the well-known surface plasmon resonance (SPR) of Au nanoparticles, indicating formation of $\mathrm{Au}$ nanoparticles in the water [28-31]. However, ablation in the toluene-ethanol solution only leads to a weak and broad absorption band around $550 \mathrm{~nm}$, as shown in Figure 2a. Similarly, for Ag, there is a strong SPR of Ag nanoparticles around $400 \mathrm{~nm}$ after ablation in water, and a very small and broad absorption band around $415 \mathrm{~nm}$ for ablation in the mixed solution, as illustrated in Figure $2 \mathrm{~b}$. Obviously, ablation in the mixed solution induces the red-shift and significant decrease of the optical absorption band for the Au@C and Ag@C samples.
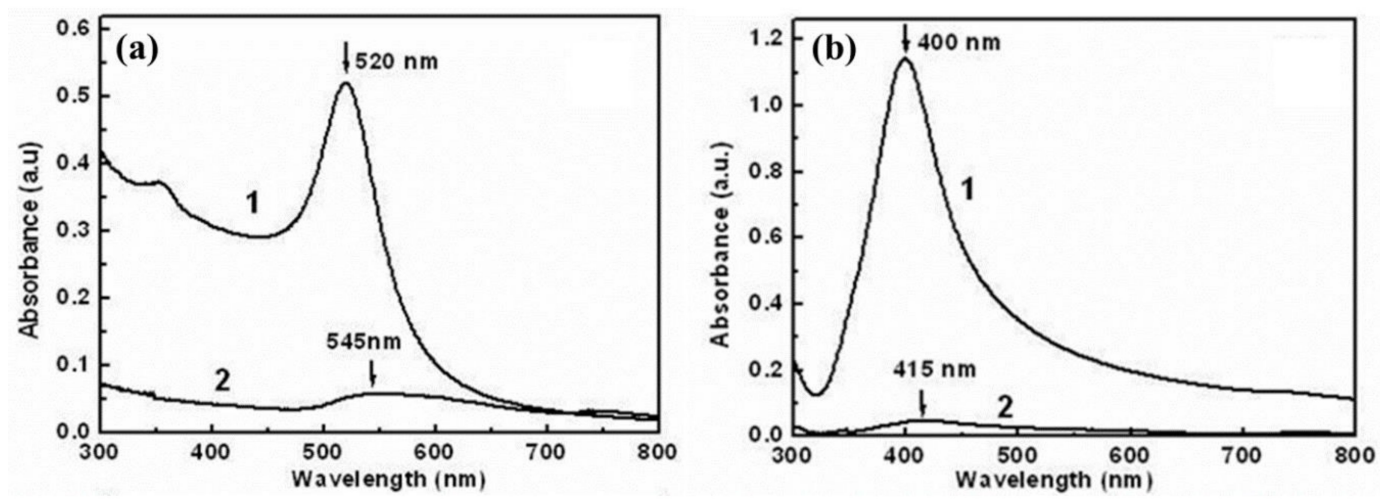

Figure 2. Optical absorbance spectra of the colloidal solutions induced by ablation of (a) Au target and (b) Ag target in solutions. Curve (1): ablation in water; and curve (2): ablation in the toluene-ethanol mixed solution with the volume ratio 9:1.

In order to further reveal the structural information about the carbon coating layer surrounding the Au nanoparticles, Raman spectral measurement is conducted for the carbon wrapped Au nanoparticles, and the result is shown in Figure 3a. It can be found that there are two broad peaks around $1350 \mathrm{~cm}^{-1}$ and $1570 \mathrm{~cm}^{-1}$, correspond to D band $\left(1355 \mathrm{~cm}^{-1}\right)$ and $\mathrm{G}$ band $\left(1590 \mathrm{~cm}^{-1}\right)$ of graphitic carbon, respectively [32,33]. For the carbon-wrapped Ag nanoparticles, the Raman spectrum is also similar, as shown in Figure $3 b$. Obviously, it can indicate that the outer shell is ultrathin carbon layer, corresponding to the results of TEM. Thus, the noble metal nanoparticles wrapped with controllable ultrathin carbon layer are fabricated by one-step based on laser ablation in ethanol-toluene mixed solutions.
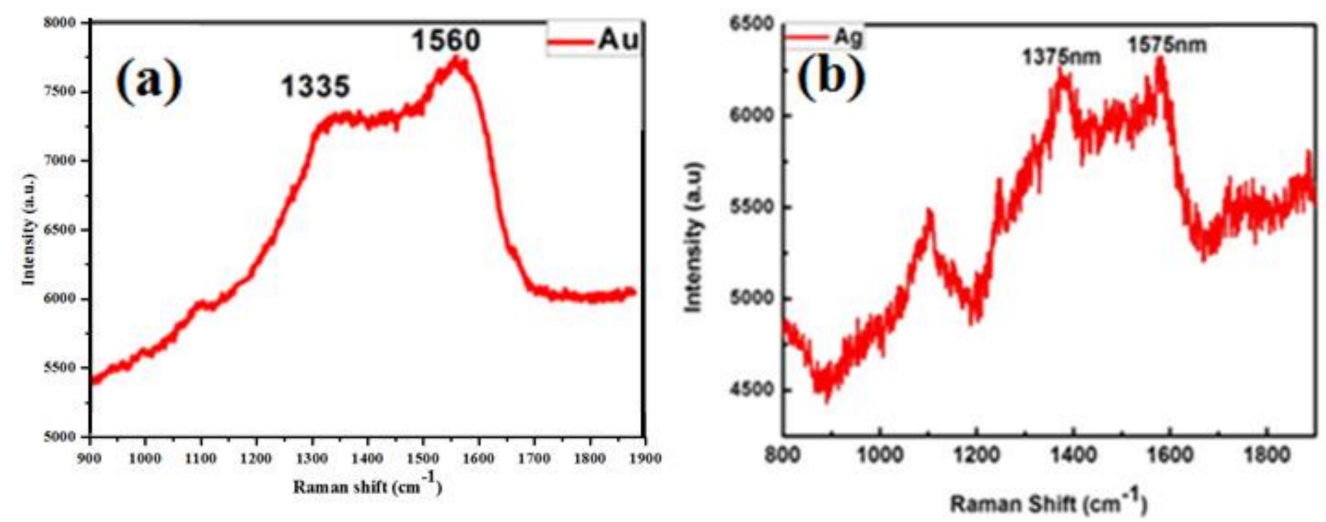

Figure 3. Raman spectrum for (a) Au@C colloidal solutions; and (b) Ag@C colloidal solutions. 
In addition, the size of the inner noble metal nanoparticles can be controlled by the ablation power. Taking the Au@C nanoparticles as an example, the nanoparticles decrease from about $20 \mathrm{~nm}$ to about $10 \mathrm{~nm}$ in mean size with the decrease of the laser power from 100 to $40 \mathrm{~mJ} /$ pulse. The other conditions are unchanged, and the results can be seen in Figure 4. However, the thickness of the outer wrapping carbon layer is almost unchanged $(\sim 2 \mathrm{~nm})$ at different ablation powers in our case. The reasons are that the higher power laser beams induce a higher density Au plasma plume on the target surface, and higher density Au particles are more easily nucleated to form larger size nanoparticles [16]. Therefore, the size of the inner noble metal nanoparticles can be controlled by adjusting the power of laser ablation, and the controllable growth of nanoparticles can be achieved by this method.
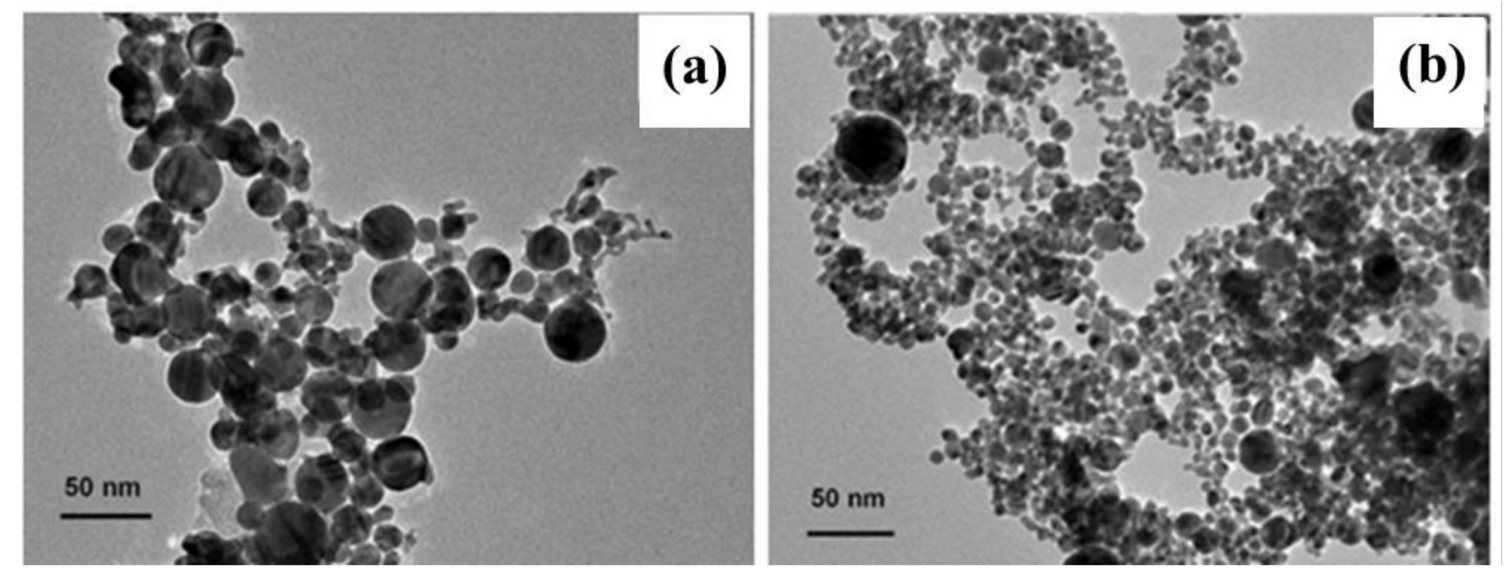

Figure 4. The TEM morphology characterization of the Au@C nanoparticles induced by the different ablation power. (a) $100 \mathrm{~mJ} /$ pulse; and (b) $40 \mathrm{~mJ} /$ pulse.

As expected, further experiments have revealed that the amount of the nanoparticles in the solution increases with the duration of the laser ablation from 2 to $60 \mathrm{~min}$, but the thickness of the carbon shell is almost unchanged. However, the composition of liquid medium strongly influences the thickness of the outer carbon shell surrounding the inner noble metal nanoparticles, as shown in Figure 5. The higher content of the carbon component leads to the thicker carbon shell, or vice versa. In the water solution, there is no carbon shell generated, as shown in Figure 5a. The D band and $\mathrm{G}$ band of graphitic carbon also cannot be seen in Figure 5b. If laser ablates in the pure ethanol under the same conditions (60 mJ/pulse) as above, we can also obtain the Au@C nanoparticles but with much smaller thickness (only $\sim 0.6 \mathrm{~nm}$ ), as shown in Figure 5c. With the increase of the toluene content in the mixed solution, the carbon shell will get thicker and thicker. With the volume ratio of 1:1, the thickness of the outer carbon shell can reach to $\sim 1.3 \mathrm{~nm}$, as shown in Figure $5 \mathrm{e}$, and $\sim 2 \mathrm{~nm}$ with the volume ratio of 9:1 shown in Figure 2. The Raman spectral measurements have confirmed existence of carbon shell on the surface of noble metal nanoparticles (similar to that shown in Figure 3). Therefore, by laser ablation in different components of organic solution, we obtained different thickness of the ultrathin carbon layer, and successfully realize the effective control of the thickness of the outer carbon shell of the noble metal nanoparticles.

In addition, as shown in Figure S7, the color of the colloid solution is changed obviously in the four solutions of water, pure ethanol, toluene-ethanol mixed solution with volume ratios of 1:1 and 9:1, respectively. The color of the colloid solution of Au nanoparticles prepared in water is more transparent and red in color (A). The color is deep purple red for the product obtained in pure ethanol (B). In the toluene-ethanol mixed solution, the color is a darker purple-brown $(C, D)$. 

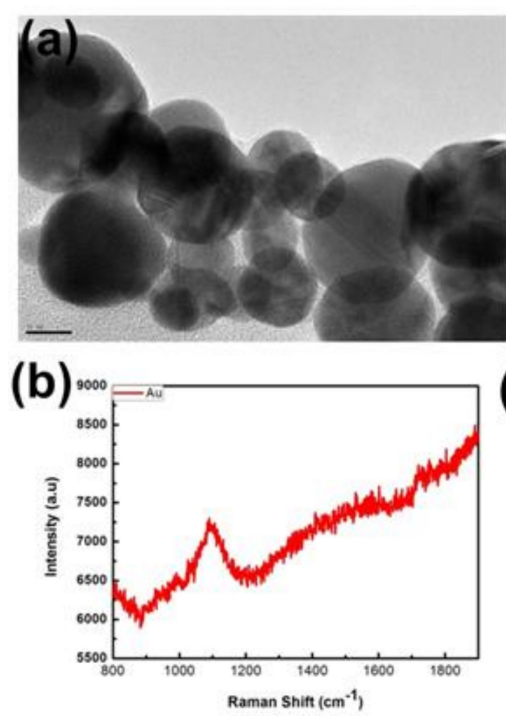
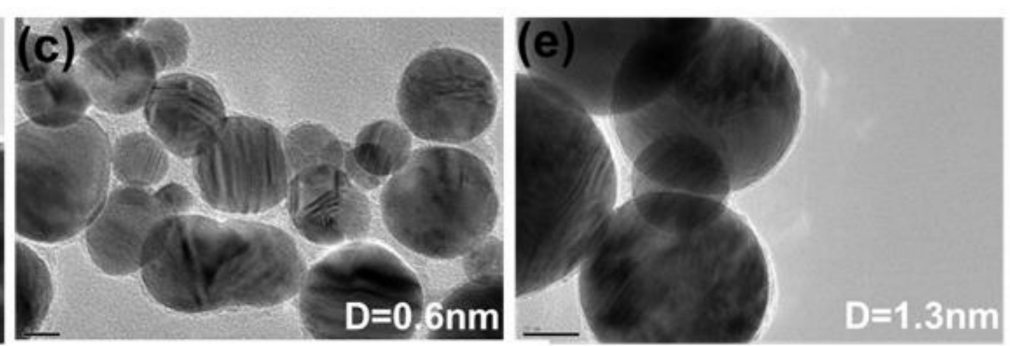

(d)

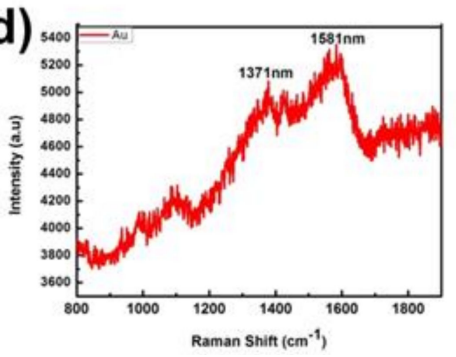

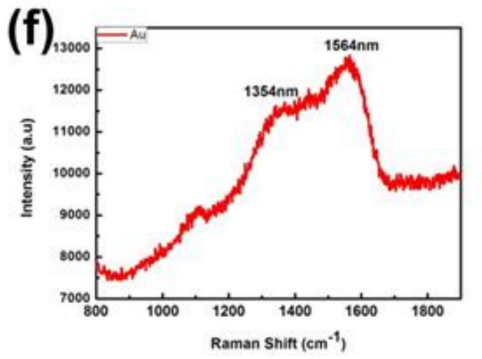

Figure 5. The TEM morphology characterization and Raman spectrum of the Au@C nanoparticles in different solutions. $(\mathbf{a}, \mathbf{b})$ water; $(\mathbf{c}, \mathbf{d})$ pure ethanol; and $(\mathbf{e}, \mathbf{f})$ toluene-ethanol mixed solution with the volume ratio of 1:1. The scales in (a), (e) and (f) are all $10 \mathrm{~nm}$.

From the above results, the formation mechanism of the carbon-wrapped noble metal nanoparticles could be easily speculated as follows. When the laser beam irradiates on the surface of metal target, the high-pressure metal plasma will be quickly formed on the solid-liquid interface [34-36]. Subsequently, such metal plasma will ultrasonically and adiabatically expand, leading to cooling of the metal plume region and hence to formation of metal nanoparticles. At the same time, C-O and $\mathrm{C}-\mathrm{C}$ ligands in ethanol or toluene molecules, at the interface between the metal plasma plume and the mixed solution, will be broken due to the extreme conditions to form carbon atoms. These carbon atoms would deposit on the preformed Au or Ag nanoparticles to form ultrathin carbon layer. For the laser ablation duration and power, it could be attributed to the number balance between the laser ablation-induced $C$ and metal nanoparticles. The longer ablation duration or higher power will not only produce the more $\mathrm{C}-\mathrm{C}$ broken bonds in the solvent molecules but also form the more $\mathrm{Au}$ or $\mathrm{Ag}$ nanoparticles. On the other hand, the thickness of the carbon shell surrounding the metal nanoparticles should significantly depend on the ability of liquid phase to supply carbon atoms at a certain laser fluence. Thus, some carbon-abundant solutions (such as toluene) could produce a thicker carbon layer than ethanol.

The $\mathrm{In}_{2} \mathrm{O}_{3}$ film is modified by $\mathrm{Au} @ \mathrm{C}$ nanoparticles (marked as $\mathrm{In}_{2} \mathrm{O}_{3} / \mathrm{Au} @ \mathrm{C}$ ) with the solution impregnation method, which the Au@C nanoparticles are prepared in toluene-ethanol mixed solution with the volume ratio of 9:1 and the power of $60 \mathrm{~mJ} /$ pulse. From the Figure $6 \mathrm{a}$, it can be seen that the $\mathrm{In}_{2} \mathrm{O}_{3}$ film on the ceramic tube is a dense granular film, and the main diffraction peaks of prepared $\mathrm{In}_{2} \mathrm{O}_{3}$ film is corresponding to cubic phase structure of $\mathrm{In}_{2} \mathrm{O}_{3}$ (JCPDS 74-1990) from its XRD pattern (Figure 6b). The TEM picture of the $\mathrm{In}_{2} \mathrm{O}_{3} / \mathrm{Au} @ \mathrm{C}$ sample and its energy spectrum can be seen in Figure $6 c$,d. On the surface of $\operatorname{In}_{2} \mathrm{O}_{3}$ film, there are many of spherical nanoparticles, which are the modifying Au@C nanoparticles. On the other hand, from the spectral peaks of Au elements, it is also proved that the Au@C nanoparticles are successfully modified on the surface of $\operatorname{In}_{2} \mathrm{O}_{3}$ granular film with solution impregnation method. The Au nanoparticles prepared by laser ablation in water solution are also modified on the $\operatorname{In}_{2} \mathrm{O}_{3}$ film (marked as $\operatorname{In}_{2} \mathrm{O}_{3} / \mathrm{Au}$ ) with the same method. 


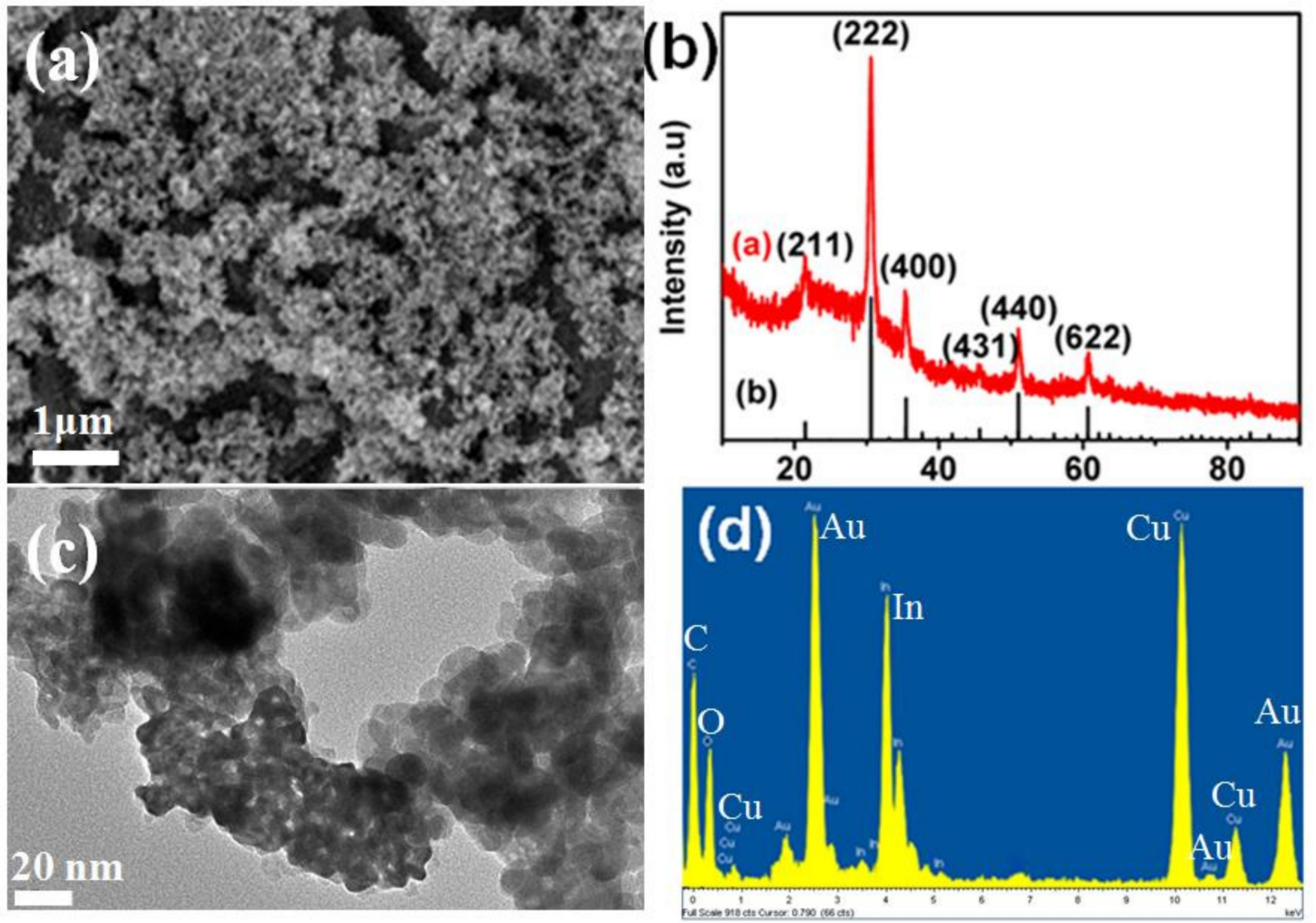

Figure 6. (a) SEM image of $\operatorname{In}_{2} \mathrm{O}_{3}$ thin film on ceramic tube; (b) corresponding XRD pattern; (c) TEM picture of as-prepared $\mathrm{Au} @ \mathrm{C}$ modified $\mathrm{In}_{2} \mathrm{O}_{3}$; and (d) its energy spectrum.

The gas-sensing properties of $\operatorname{In}_{2} \mathrm{O}_{3}, \operatorname{In}_{2} \mathrm{O}_{3} / \mathrm{Au}$ and $\operatorname{In}_{2} \mathrm{O}_{3} / \mathrm{Au} @ \mathrm{C}$ films to $\mathrm{H}_{2} \mathrm{~S}$ gas are measured at room temperature from 1 to $5 \mathrm{ppm}$ with a relative humidity (RH) of $60 \%$, and the results can be seen in Figure 7 and Figure S8. For the $\operatorname{In}_{2} \mathrm{O}_{3}$ film at a concentration of 1 ppm, it has an excellent gas-sensitive response to $\mathrm{H}_{2} \mathrm{~S}$ gas (about 90 ) at room temperature, but it cannot be recovered, as shown in Figure S8. It can be seen that for the $\mathrm{In}_{2} \mathrm{O}_{3} / \mathrm{Au} @ \mathrm{C}$ films the sensing sensitivity is 52, 97, 141, 178 , and 228 from the concentration of 1 to $5 \mathrm{ppm}$ to $\mathrm{H}_{2} \mathrm{~S}$ with $\mathrm{RH}=60 \%$ at room temperature, respectively. For the $\mathrm{In}_{2} \mathrm{O}_{3} / \mathrm{Au}$ films that is $24,35,47,62$, and 78 at the same conditions, respectively. Thus, the $\mathrm{In}_{2} \mathrm{O}_{3} / \mathrm{Au} @ \mathrm{C}$ films have a better gas sensing sensitivity to $\mathrm{H}_{2} \mathrm{~S}$ gas than $\mathrm{In}_{2} \mathrm{O}_{3} / \mathrm{Au}$ films. However, the $\mathrm{In}_{2} \mathrm{O}_{3} / \mathrm{Au}$ films have a better response and recovery time (defined as the times to reach $90 \%$ of resistance change) shown in Figure $7 \mathrm{a}$. For example, at the concentration of $4 \mathrm{ppm}$ to $\mathrm{H}_{2} \mathrm{~S}$ gas, the response and recovery time is 9 and $20 \mathrm{~s}$ for the $\mathrm{In}_{2} \mathrm{O}_{3} / \mathrm{Au}$ films, which is 16 and $33 \mathrm{~s}$ for the $\mathrm{In}_{2} \mathrm{O}_{3} / \mathrm{Au} @ \mathrm{C}$ films. That may be related to the catalytic ability of Au nanoparticles, and for the $\mathrm{In}_{2} \mathrm{O}_{3} / \mathrm{Au}$ films more Au nanoparticles are easily exposed to $\mathrm{H}_{2} \mathrm{~S}$ gas, which are not coated by carbon layers. They will have a better catalytic performance and response and recovery capability. Additionally, for the $\mathrm{In}_{2} \mathrm{O}_{3} / \mathrm{Au} @ \mathrm{C}$ films at the concentration of $5 \mathrm{ppm}$ to $\mathrm{H}_{2} \mathrm{~S}$ gas there is a sharp response curve, but it has achieved sensor signal saturation, which can be seen in the later discussion (the reproducibility response curves of $\mathrm{In}_{2} \mathrm{O}_{3} / \mathrm{Au} @ \mathrm{C}$ sensor to $\mathrm{H}_{2} \mathrm{~S}$ with a concentration of $5 \mathrm{ppm}$ at room temperature in Figure 8). Similar to most semiconductor material, $\mathrm{In}_{2} \mathrm{O}_{3}$ is an n-type semiconducting metal oxide. When it is exposed to air, oxygen would be adsorbed on the surface of the $\mathrm{In}_{2} \mathrm{O}_{3}$ film and turned into chemisorbed oxygen, such as $\mathrm{O}_{2}{ }^{2-}$ or $\mathrm{O}_{2}{ }^{-}$, which plays a role as trap electrons and surface acceptors, and the resistance of the $\operatorname{In}_{2} \mathrm{O}_{3}$ film increases. If the $\operatorname{In}_{2} \mathrm{O}_{3}$ film is exposed to $\mathrm{H}_{2} \mathrm{~S}$ gas, which is a strong reducing gas, the $\mathrm{H}_{2} \mathrm{~S}$ molecules will react with the $\mathrm{O}_{2}{ }^{2-}$ or $\mathrm{O}_{2}{ }^{-}$adsorbed on the surface of $\operatorname{In}_{2} \mathrm{O}_{3}$ film. Then the captured electrons will release back to the bulk, and the resistance of the $\operatorname{In}_{2} \mathrm{O}_{3}$ film decrease. Thus, the response of the samples to $\mathrm{H}_{2} \mathrm{~S}$ gas $\mathrm{R}_{\mathrm{air}} / \mathrm{R}_{\mathrm{g}}$ will drastically increase. When the $\operatorname{In}_{2} \mathrm{O}_{3}$ film once is exposed to air, it will return to the initial state, and so 
on and so on. Exposed to high concentration of $\mathrm{H}_{2} \mathrm{~S}$ gas, the decrease of resistance of the $\mathrm{In}_{2} \mathrm{O}_{3}$ film is more obvious. The Au nanoparticles and carbon shell also plays an important role in the process, and the affect mechanism will discussed in detail later. For the two films, there is also a good linear relationship with concentration of $\mathrm{H}_{2} \mathrm{~S}$ gas as shown in Figure 7b, which is favorable to the practical application. For each concentration of $\mathrm{H}_{2} \mathrm{~S}$ gas, the number of repeat measurements is six and the resulting standard deviation for the two films can also be seen in Figure $7 \mathrm{~b}$.
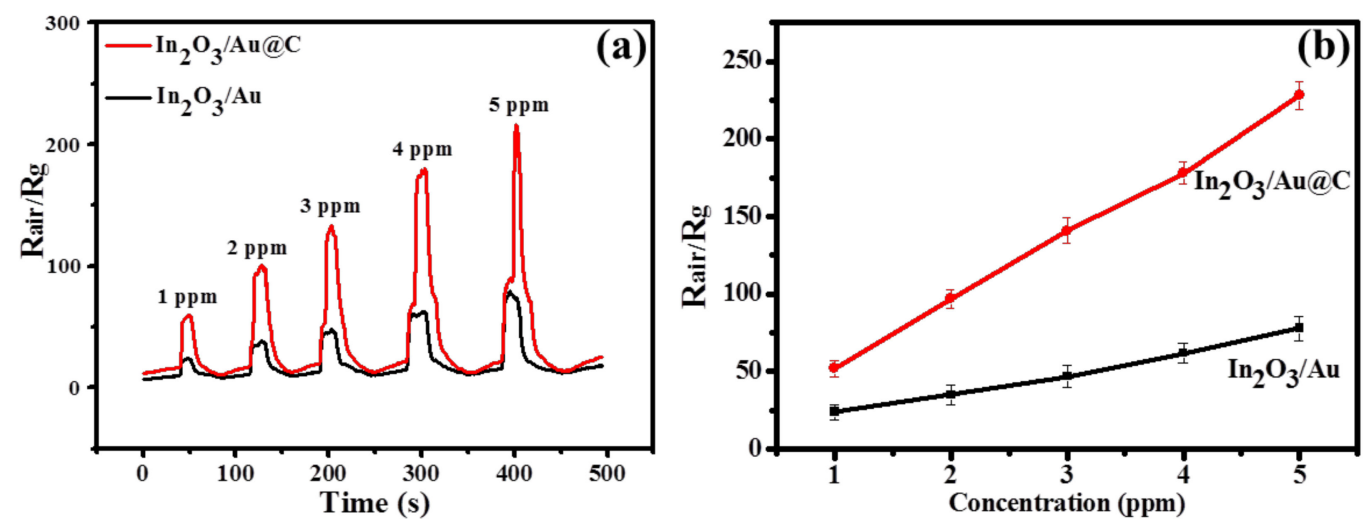

Figure 7. (a) The response curves as functions of test time to $\mathrm{H}_{2} \mathrm{~S}$ and (b) the sensitivity versus $\mathrm{H}_{2} \mathrm{~S}$ concentration of $\mathrm{In}_{2} \mathrm{O}_{3} / \mathrm{Au} @ \mathrm{C}$ and $\mathrm{In}_{2} \mathrm{O}_{3} /$ Au sensor at a concentration ranging from 1-5 ppm with $\mathrm{RH}=60 \%$ at room temperature.
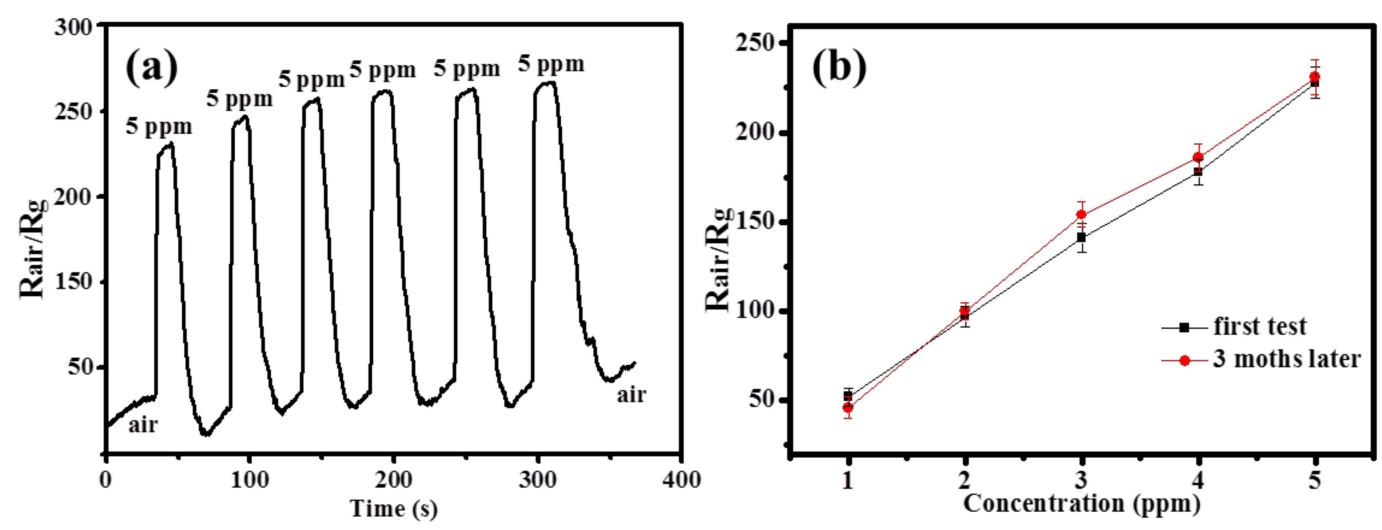

Figure 8. (a) The reproducibility response curves of $\mathrm{In}_{2} \mathrm{O}_{3} / \mathrm{Au} @ \mathrm{C}$ sensor to $\mathrm{H}_{2} \mathrm{~S}$ with a concentration of $5 \mathrm{ppm}$ at room temperature; and (b) the concentration-dependent response curve to $\mathrm{H}_{2} \mathrm{~S}$ from 1-5 ppm at room temperature measured before and after three months for $\operatorname{In}_{2} \mathrm{O}_{3} / \mathrm{Au} @ \mathrm{C}$ sensor. All are tested under the ambience with $60 \% \mathrm{RH}$.

From the above results, it can be seen that the $\mathrm{In}_{2} \mathrm{O}_{3}$ films modified by Au@C have the best sensitivity. Thus, the practical performances of the $\mathrm{In}_{2} \mathrm{O}_{3} / \mathrm{Au} @ \mathrm{C}$ sensor are tested. In Figure 8a, it can be seen that the $\mathrm{In}_{2} \mathrm{O}_{3} / \mathrm{Au} @ \mathrm{C}$ gas sensor still have a similar response curves in the six cycles, and the sensing sensitivity is $237,246,252,257,258$, and 261 with $60 \% \mathrm{RH}$ to $\mathrm{H}_{2} \mathrm{~S}$ gas with a concentration of $5 \mathrm{ppm}$ at room temperature, respectively. As the number of cycles increases, the sensing sensitivity for the $\mathrm{H}_{2} \mathrm{~S}$ gas increases as well. The reason is that at room temperature when the sample is exposed to $\mathrm{H}_{2} \mathrm{~S}$ gas with a concentration of $5 \mathrm{ppm}$, it will lead to the decrease of resistance of the $\mathrm{In}_{2} \mathrm{O}_{3} / \mathrm{Au} @ \mathrm{C}$ sample and the dramatic increase of the test signal $\left(R_{a i r} / R_{g}\right)$. When it is exposed to air, the sample will return to the initial state and the test signal will decrease. However, in this process the ultrathin carbon shell may adsorb some residual $\mathrm{H}_{2} \mathrm{~S}$ gas, which results in the resistance of the $\mathrm{In}_{2} \mathrm{O}_{3} / \mathrm{Au} @ \mathrm{C}$ sample increase in air compared to the first state. As the number of cycles increases, more residual $\mathrm{H}_{2} \mathrm{~S}$ gas may be adsorbed on the surface of ultrathin carbon shell, and the test signal also drift higher. 
Further, the concentration dependent response curve to $\mathrm{H}_{2} \mathrm{~S}$ from 1-5 ppm at room temperature with $60 \% \mathrm{RH}$ is measured after three months for the $\operatorname{In}_{2} \mathrm{O}_{3} / \mathrm{Au} @ \mathrm{C}$ sensor, and only a slight change happened in three months, as shown in Figure 8b. It indicates that the $\mathrm{In}_{2} \mathrm{O}_{3} / \mathrm{Au} @ \mathrm{C}$ sensor also has a good long-term stability. Additionally, the resulting standard deviation is shown in Figure $8 \mathrm{~b}$ and the number of repeat measurements is six for each concentration of $\mathrm{H}_{2} \mathrm{~S}$ gas.

The selectivity is very important for a gas sensor, so the $\operatorname{In}_{2} \mathrm{O}_{3} / \mathrm{Au} @ \mathrm{C}$ sensor is exposed to six other kinds of oxidizing or reducing interferential gases at room temperature with $60 \% \mathrm{RH}$, such as $\mathrm{C}_{3} \mathrm{H}_{6} \mathrm{O}, \mathrm{H}_{2}, \mathrm{C}_{2} \mathrm{H}_{6} \mathrm{O}, \mathrm{NH}_{3}, \mathrm{CH}_{4}$, and $\mathrm{SO}_{2}$, respectively. As shown in Figure $9 \mathrm{a}$, the sensing sensitivity to the seven kinds of gases is $7,3,20,31,9,41$, and 228, respectively, the concentration of which is $5 \mathrm{ppm}$, including $\mathrm{H}_{2} \mathrm{~S}$ gas. It can be seen that the sensitivity to $\mathrm{H}_{2} \mathrm{~S}$ gas is highest, which is several or more than one hundred times that of other gases. As the consequence, the $\operatorname{In}_{2} \mathrm{O}_{3} / \mathrm{Au} @ \mathrm{C}$ sensor will have an excellent selective gas sensing to $\mathrm{H}_{2} \mathrm{~S}$ in the real environment. Further, the response curves to $\mathrm{H}_{2} \mathrm{~S}$ with different $\mathrm{RH}$ values at a concentration of $5 \mathrm{ppm}$ are shown in Figure $9 \mathrm{~b}$ at room temperature, and the sensing sensitivity is $177,198,228$, and 206 , respectively. The response curve to $\mathrm{H}_{2} \mathrm{~S}$ increases to the maxima with rise of the ambient $\mathrm{RH}$ value up to $60 \%$, and they decreases at a higher RH. Obviously, with 60\% RH the $\mathrm{In}_{2} \mathrm{O}_{3} / \mathrm{Au} @ \mathrm{C}$ sensor has the best response ability.
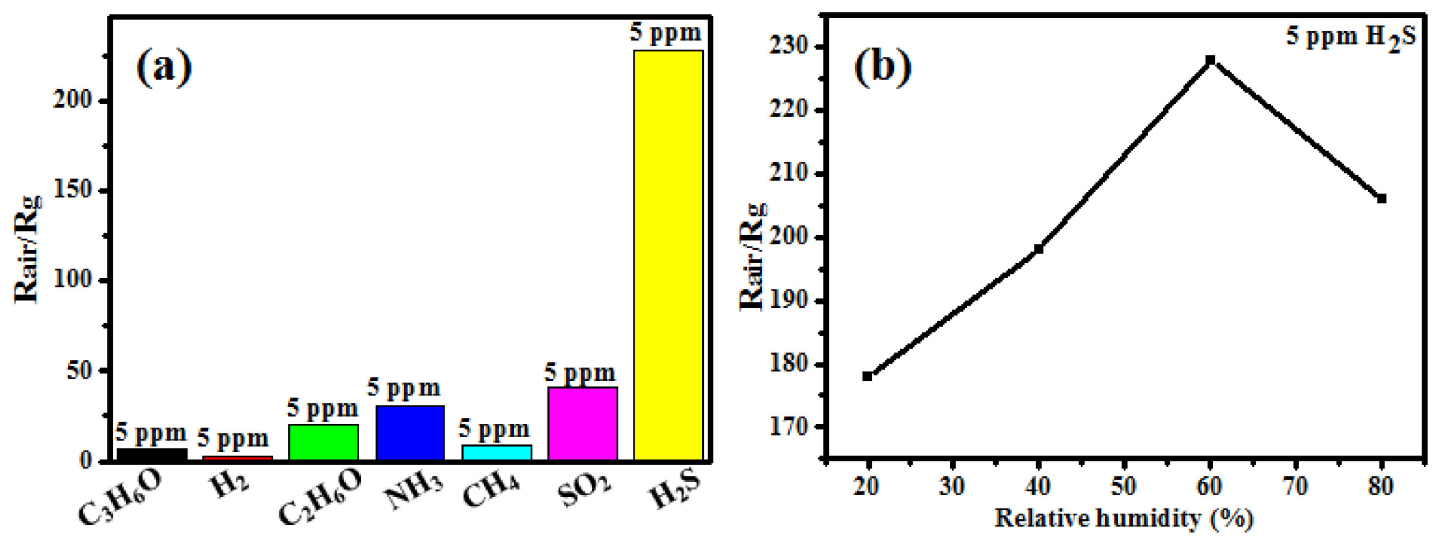

Figure 9. (a) Some potential interferential gases for the $\mathrm{In}_{2} \mathrm{O}_{3} / \mathrm{Au} @ \mathrm{C}$ sensor at room temperature with $60 \% \mathrm{RH}$ compared to $\mathrm{H}_{2} \mathrm{~S}$; and (b) the steady response curve to $\mathrm{H}_{2} \mathrm{~S}$ with a concentration of $5 \mathrm{ppm}$ the at room temperature as a function of the ambient humidity from 20 to $80 \%$.

From the above results, it is known that the $\mathrm{Au}$ and $\mathrm{Au} @ \mathrm{C}$ nanoparticles can improve the performance of $\mathrm{In}_{2} \mathrm{O}_{3}$ gas sensors. This is due to the electronic sensitization mechanism and chemical sensitization mechanism of nanoparticles, and the nanoparticles prepared by laser ablation of the metal targets in liquids have a large number of defects and chemical dangling bonds in the inner and on the surface of nanoparticles, which have higher activity [15]. On the one hand, the nanoparticles can enhance the electron density on the surface of the $\operatorname{In}_{2} \mathrm{O}_{3}$ film and adjust the resistance by the electronic sensitization mechanism. On the other hand, they have higher catalytic activity by the chemical sensitization mechanism and the spillover effect in the catalysis process [37]. They may provide more active sites for the adsorption of molecular oxygen and tracer gas. Then more electrons are provided for the redox reaction occur on the surface of $\operatorname{In}_{2} \mathrm{O}_{3}$ film, and the speed of gas sensitive reaction is accelerated. In addition, it is also observed that the $\mathrm{In}_{2} \mathrm{O}_{3}$ film modified by $\mathrm{Au} @ \mathrm{C}$ nanoparticles has better gas sensing properties than that modified by Au nanoparticles, indicating that the ultrathin carbon layer plays an important role on the gas sensing process. This is due to the unique electronic properties of carbon materials, such as high carrier mobility and the high sensitivity to the changes of resistance [38-40]. The ultrathin carbon layer can rapidly transform the electric carriers generated from the sensing process, and local p-n heterojunctions are created between carbon layer and $\operatorname{In}_{2} \mathrm{O}_{3}$ film, in which the carbon layer plays a role as a p-type semiconductor [37]. As a results, the performance 
of gas sensor is enhanced more. From the HRTEM of Au@C sample (Figure 1), it can be seen that the outer ultrathin carbon layer is about $2 \mathrm{~nm}$ in thickness with several carbon shells, which cannot prevent the contact of the analyte gas with the Au nanoparticles. The analyte gas can pierce through the outer carbon shells easily [41]. Finally, the more specific impact mechanisms will be studied in detail in future investigations.

\section{Conclusions}

In summary, the noble metal nanoparticles wrapped by an ultrathin carbon layer were prepared in one step based on laser ablation of the metal targets in the carbon-containing solutions. Laser irradiation of the targets not only formed the metal plasma instantly, but also the carbon atoms by breaking C-O and C-C ligands in the solution, which led to the formation of metal nanoparticles and subsequent carbon-wrapping. The thickness of the wrapped carbon layer could be tuned and controlled mainly by the carbon content in solutions, and it would reduce to $\sim 1.3 \mathrm{~nm}$ by changing the proportion of toluene in the ethanol-toluene mixed solution. The $\mathrm{In}_{2} \mathrm{O}_{3}$ film modified by Au@C nanoparticles shows better gas sensitivity performance to $\mathrm{H}_{2} \mathrm{~S}$ gas from 1 to $5 \mathrm{ppm}$ at room temperature, and the ultrathin carbon layer plays an important role on the gas sensing process. This study could also be suitable for the preparation of other metal nanoparticles with wrapped ultrathin carbon layers.

Supplementary Materials: The following are available online at http:/ /www.mdpi.com/2072-666X/9/6/278/s1, Figure S1: The energy spectrum of Au@C nanoparticles products by ablation of Au target in the toluene-ethanol solution with the volume ratio 9:1, Figure S2: TEM image of products induced by ablation of Au target in the water and the inset: selected area electronic diffraction of the particles, showing formation of Au nanoparticles with the size below $20 \mathrm{~nm}$, Figure S3: TEM image of products induced by ablation of Ag target in the water, Figure S4: The products induced by ablation of Ag target in the toluene-ethanol solution with the volume ratio 9:1. (a): TEM image. (b): particle size distribution (data from (a)). (c): The local magnified image of (a). The inset is the selected area electronic diffraction, Figure S5: The energy spectrum of Ag@C nanoparticles products by ablation of Ag target in the toluene-ethanol solution with the volume ratio 9:1, Figure S6: The gravimetric analysis curve of the Au@C nanoparticles sample, Figure S7: The colour of the colloid solution obtained in the four solutions of (A) water; (B) pure ethanol; (C) toluene-ethanol mixed solution with the volume ratio of 1:1; and (D) toluene-ethanol mixed solution with the volume ratio of 9:1, Figure S8: The response curve (Rair/Rg) as function of test time to $\mathrm{H} 2 \mathrm{~S}$ gas with $1 \mathrm{ppm}$ concentration at room temperature

Author Contributions: X.X. and G.D. conceived and designed the experiments; X.X. performed the experiments; L.G. analyzed the data; L.G. and X.X. wrote the paper, and they contributed equally and were co-first authors.

Acknowledgments: The authors acknowledge the financial supports from National Key R and D Program of China (2016YFC0201103), and financial supports from the Natural Science Foundation of China (grant no. 51471161 and 11674320), Anhui Provincial Natural Science Foundation for Distinguished Young Scholar (1408085J10), Youth Innovation Promotion Association CAS, and the Key Research Projects of the Frontier Science CAS (QYZDB-SSW-JSC017).

Conflicts of Interest: The authors declare no conflict of interest.

\section{References}

1. Tan, G.Q.; Wu, F.; Yuan, Y.F.; Chen, R.J.; Zhao, T.; Yao, Y.; Qian, J.; Liu, J.R.; Ye, Y.S.; Shahbazian-Yassar, R.; et al. Freestanding three-dimensional core-shell nanoarrays for lithium-ion battery anodes. Nat. Commun. 2016, 7. [CrossRef] [PubMed]

2. Chen, X.S.; Liu, G.B.; Zheng, W.; Feng, W.; Cao, W.W.; Hu, W.P.; Hu, P.A. Vertical 2D MoO $2 / \mathrm{MoSe}_{2}$ Core-Shell Nanosheet Arrays as High-Performance Electrocatalysts for Hydrogen Evolution Reaction. Adv. Funct. Mater. 2016, 26, 8537-8544. [CrossRef]

3. Zhu, H.; Zhang, J.F.; Yanzhang, R.P.; Du, M.L.; Wang, Q.F.; Gao, G.H.; Wu, J.D.; Wu, G.M.; Zhang, M.; Liu, B.; et al. When Cubic Cobalt Sulfide Meets Layered Molybdenum Disulfide: A Core-Shell System Toward Synergetic Electrocatalytic Water Splitting. Adv. Mater. 2015, 27, 4752-4759. [CrossRef] [PubMed]

4. Li, J.F.; Zhang, Y.J.; Ding, S.Y.; Panneerselvam, R.; Tian, Z.Q. Core-Shell Nanoparticle-Enhanced Raman Spectroscopy. Chem. Rev. 2017, 117, 5002-5069. [CrossRef] [PubMed]

5. Xu, W.G.; Xiao, J.Q.; Chen, Y.F.; Chen, Y.B.; Ling, X.; Zhang, J. Graphene-Veiled Gold Substrate for Surface-Enhanced Raman Spectroscopy. Adv. Mater. 2013, 25, 928-933. [CrossRef] [PubMed] 
6. Boies, A.M.; Lei, P.; Calder, S.; Girshick, S.L. Gas-phase production of gold-decorated silica nanoparticles. Nanotechnology 2011, 22. [CrossRef] [PubMed]

7. Seipenbusch, M.; Binder, A. Structural Stabilization of Metal Nanoparticles by Chemical Vapor Deposition-Applied Silica Coatings. J. Phys. Chem. C 2009, 113, 20606-20610. [CrossRef]

8. Boies, A.M.; Roberts, J.T.; Girshick, S.L.; Zhang, B.; Nakamura, T.; Mochizuki, A. SiO 2 coating of silver nanoparticles by photoinduced chemical vapor deposition. Nanotechnology 2009, 20. [CrossRef] [PubMed]

9. Gao, L.J.; He, J.H. A facile dip-coating approach based on three silica sols to fabrication of broadband antireflective superhydrophobic coatings. J. Colloid Interface Sci. 2013, 400, 24-30. [CrossRef] [PubMed]

10. Malynych, S.; Luzinov, I.; Chumanov, G. Poly(vinyl pyridine) as a universal surface modifier for immobilization of nanoparticles. J. Phys. Chem. B 2002, 106, 1280-1285. [CrossRef]

11. Li, J.F.; Huang, Y.F.; Ding, Y.; Yang, Z.L.; Li, S.B.; Zhou, X.S.; Fan, F.R.; Zhang, W.; Zhou, Z.Y.; Wu, D.Y.; et al. Shell-isolated nanoparticle-enhanced Raman spectroscopy. Nature 2010, 464, 392-395. [CrossRef] [PubMed]

12. Nikolov, A.S.; Balchev, I.I.; Nedyalkov, N.N.; Kostadinov, I.K.; Karashanova, D.B.; Atanasova, G.B. Influence of the laser pulse repetition rate and scanning speed on the morphology of Ag nanostructures fabricated by pulsed laser ablation of solid target in water. Appl. Phys. A Mater. Sci. Process. 2017, 123, 719. [CrossRef]

13. Li, S.; Zhang, H.; Xu, L.L.; Chen, M. Laser-induced construction of multi-branched CuS nanodendrites with excellent surface-enhanced Raman scattering spectroscopy in repeated applications. Opt. Express 2017, 25, 16204-16213. [CrossRef] [PubMed]

14. Bozon-Verduraz, F.; Brayner, R.; Voronov, V.V.; Kirichenko, N.A.; Simakin, A.V.; Shafeev, G.A. Production of nanoparticles by laser-induced ablation of metals in liquids. Quantum Electron. 2003, 33, 714-720. [CrossRef]

15. Bauer, F.; Michalowski, A.; Nolte, S. Residual Heat in Ultra-Short Pulsed Laser Ablation of Metals. J. Laser Micro Nanoeng. 2015, 10, 325-328. [CrossRef]

16. Garcia Guilen, G.; Mendivil Palma, M.I.; Krishnan, B.; Avellaneda, D.; Castillo, G.A.; Das Roy, T.K.; Shaji, S. Structure and morphologies of $\mathrm{ZnO}$ nanoparticles synthesized by pulsed laser ablation in liquid: Effects of temperature and energy fluence. Mater. Chem. Phys. 2015, 162, 561-570. [CrossRef]

17. Lasemi, N.; Pacher, U.; Rentenberger, C.; Bomati-Miguel, O.; Kautek, W. Laser-Assisted Synthesis of Colloidal $\mathrm{Ni} / \mathrm{NiOx}$ Core/Shell Nanoparticles in Water and Alcoholic Solvents. Chemphyschem 2017, 18, 1118-1124. [CrossRef] [PubMed]

18. Hua, Z.Q.; Qiu, Z.L.; Li, Y.; Zeng, Y.; Wu, Y.; Tian, X.M.; Wang, M.J.; Li, E.P. A theoretical investigation of the power-law response of metal oxide semiconductor gas sensors II: Size and shape effects. Sens. Actuator B Chem. 2018, 255, 3541-3549. [CrossRef]

19. Yin, C.Q.; Gao, L.; Zhou, F.; Duan, G.T. Facile Synthesis of Polyaniline Nanotubes Using Self-Assembly Method Based on the Hydrogen Bonding: Mechanism and Application in Gas Sensing. Polymers 2017, 9, 544. [CrossRef]

20. Su, X.S.; Gao, L.; Zhou, F.; Duan, G.T. A substrate-independent fabrication of hollow sphere arrays via template-assisted hydrothermal approach and their application in gas sensing. Sens. Actuator B Chem. 2017, 251, 74-85. [CrossRef]

21. Song, Z.L.; Liu, J.Y.; Liu, Q.; Yu, H.X.; Zhang, W.K.; Wang, Y.; Huang, Z.; Zang, J.F.; Liu, H. Enhanced H2S gas sensing properties based on $\mathrm{SnO}_{2}$ quantum wire/reduced graphene oxide nanocomposites: Equilibrium and kinetics modeling. Sens. Actuator B Chem. 2017, 249, 632-638. [CrossRef]

22. Zhang, S.; Song, P.; Zhang, J.; Yan, H.H.; Li, J.; Yang, Z.X.; Wang, Q. Highly sensitive detection of acetone using mesoporous $\mathrm{In}_{2} \mathrm{O}_{3}$ nanospher es decorated with Au nanoparticles. Sens. Actuator B Chem. 2017, 242, 983-993. [CrossRef]

23. Park, $\mathrm{S}$. Acetone gas detection using $\mathrm{TiO}_{2}$ nanoparticles functionalized $\mathrm{In}_{2} \mathrm{O}_{3}$ nanowires for diagnosis of diabetes. J. Alloys Compd. 2017, 696, 655-662. [CrossRef]

24. Pang, Z.Y.; Nie, Q.X.; Wei, A.F.; Yang, J.; Huang, F.L.; Wei, Q.F. Effect of $\mathrm{In}_{2} \mathrm{O}_{3}$ nanofiber structure on the ammonia sensing performances of $\mathrm{In}_{2} \mathrm{O}_{3}$ /PANI composite nanofibers. J. Mater. Sci. 2017, 52, 686-695. [CrossRef]

25. Plashnitsa, V.V.; Elumalai, P.; Kawaguchi, T.; Fujio, Y.; Miura, N. Highly Sensitive and Selective Zirconia-Based Propene Sensor using Nanostructured Gold Sensing Electrodes Fabricated from Colloidal Solutions. J. Phys. Chem. C 2009, 113, 7857-7862. [CrossRef] 
26. Vargas-Garcia, R.; Romero-Serrano, A.; Angeles-Hernandez, M.; Chavez-Alcala, F.; Gomez-Yanez, C. Pt electrode-based sensor prepared by metal organic chemical vapor deposition for oxygen activity measurements in glass melts. Sens. Mater. 2002, 14, 47-56.

27. Mirzaei, A.; Janghorban, K.; Hashemi, B.; Neri, G. Metal-core@metal oxide-shell nanomaterials for gas-sensing applications: A review. J. Nanopart. Res. 2015, 17, 371. [CrossRef]

28. Bianco, G.V.; Giangregorio, M.M.; Losurdo, M.; Capezzuto, P.; Bruno, G. Supported Faceted Gold Nanoparticles with Tunable Surface Plasmon Resonance for NIR-SERS. Adv. Funct. Mater. 2012, 22, 5081-5088. [CrossRef]

29. Chen, J.Y.; Chen, Y.C. A label-free sensing method for phosphopeptides using two-layer gold nanoparticle-based localized surface plasma resonance spectroscopy. Anal. Bioanal. Chem. 2011, 399, 1173-1180. [CrossRef] [PubMed]

30. Lee, K.S.; El-Sayed, M.A. Gold and silver nanoparticles in sensing and imaging: Sensitivity of plasmon response to size, shape, and metal composition. J. Phys. Chem. B 2006, 110, 19220-19225. [CrossRef] [PubMed]

31. Norman, T.J.; Grant, C.D.; Magana, D.; Zhang, J.Z.; Liu, J.; Cao, D.L.; Bridges, F.; Van Buuren, A. Near infrared optical absorption of gold nanoparticle aggregates. J. Phys. Chem. B 2002, 106, 7005-7012. [CrossRef]

32. Boskovic, B.O.; Stolojan, V.; Khan, R.U.A.; Haq, S.; Silva, S.R.P. Large-area synthesis of carbon nanofibres at room temperature. Nat. Mater. 2002, 1, 165-168. [CrossRef] [PubMed]

33. Nemanich, R.J.; Solin, S.A. 1st-order and 2nd-order raman-scattering from finite-size crystals of graphite. Phys. Rev. B 1979, 20, 392-401. [CrossRef]

34. Huang, C.C.; Yeh, C.S.; Ho, C.J. Laser ablation synthesis of spindle-like gallium oxide hydroxide nanoparticles with the presence of cationic cetyltrimethylammonium bromide. J. Phys. Chem. B 2004, 108, 4940-4945. [CrossRef]

35. Mafune, F.; Kohno, J.; Takeda, Y.; Kondow, T.; Sawabe, H. Formation of gold nanoparticles by laser ablation in aqueous solution of surfactant. J. Phys. Chem. B 2001, 105, 5114-5120. [CrossRef]

36. Patil, P.P.; Phase, D.M.; Kulkarni, S.A.; Ghaisas, S.V.; Kulkarni, S.K.; Kanetkar, S.M.; Ogale, S.B.; Bhide, V.G. Pulsed-laser induced reactive quenching at a liquid-solid interface-aqueous oxidation of iron. Phys. Rev. Lett. 1987, 58, 238-241. [CrossRef] [PubMed]

37. Meng, F.; Zheng, H.; Chang, Y.; Zhao, Y.; Li, M.; Wang, C.; Sun, Y.; Liu, J. One-Step Synthesis of $\mathrm{Au} / \mathrm{SnO}_{2} /$ RGO Nanocomposites and Their VOC Sensing Properties. IEEE Trans. Nanotechnol. 2018, 17, 212-219. [CrossRef]

38. Javey, A.; Guo, J.; Wang, Q.; Lundstrom, M.; Dai, H.J. Ballistic carbon nanotube field-effect transistors. Nature 2003, 424, 654-657. [CrossRef] [PubMed]

39. Heinze, S.; Tersoff, J.; Martel, R.; Derycke, V.; Appenzeller, J.; Avouris, P. Carbon nanotubes as Schottky barrier transistors. Phys. Rev. Lett. 2002, 89, 106801. [CrossRef] [PubMed]

40. Cong, H.; Yang, F.; Xue, C.L.; Yu, K.; Zhou, L.; Wang, N.; Cheng, B.W.; Wang, Q.M. Multilayer Graphene-GeSn Quantum Well Heterostructure SWIR Light Source. Small 2018, 14. [CrossRef] [PubMed]

41. Zhang, Y.; Li, Y.; Jiang, Y.; Li, Y.; Li, S. The synthesis of Au@C@Pt core-double shell nanocomposite and its application in enzyme-free hydrogen peroxide sensing. Appl. Surf. Sci. 2016, 378, 375-383.

(C) 2018 by the authors. Licensee MDPI, Basel, Switzerland. This article is an open access article distributed under the terms and conditions of the Creative Commons Attribution (CC BY) license (http://creativecommons.org/licenses/by/4.0/). 